\title{
Posthepatectomy Liver Failure
}

\author{
Teresa Schreckenbach Juliane Liese Wolf O. Bechstein Christian Moench \\ Department of General and Visceral Surgery, Johann Wolfgang Goethe University, Frankfurt am Main, Germany
}

\section{Key Words}

Posthepatectomy liver failure - Risk analysis • Prevention •

Future liver remnant $\cdot$ Cirrhosis

\begin{abstract}
Background: Posthepatectomy liver failure (PHLF) is one of the most serious complications after liver resection and is still reported in up to $8 \%$ after liver resection. Aims: To provide an overview about the current status of risk analysis and definition of PHLF. Prevention and treatment is also discussed. Methods: A literature review was carried out on PubMed using the terms 'liver failure', 'posthepatectomy' and 'liver surgery' to search relevant papers. Discussion: PHLF remains a serious problem in patients undergoing major liver resection. Adequate preoperative risk assessment and an optimal postoperative treatment are essential for PHLF prevention.

Copyright ๑ 2012 S. Karger AG, Base
\end{abstract}

\section{Introduction}

Posthepatectomy liver failure (PHLF) is one of the most serious complications after liver resection. Although morbidity and mortality after liver surgery improved over the past 10 years, PHLF is still reported in up to $8 \%$ depending on the patient's condition and on functional reserve of the liver before resection [1-3].

Knowledge of the incidence as well as risk factors is essential to prevent PHLF. Scoring systems can be useful to stratify between functional respectability and non-re- spectability. After surgery, these systems may be useful for the early diagnosis of PHLF resulting in adequate treatment at an early time point.

This article gives a short overview about a current status of risk analysis, prevention and treatment of liver failure after liver surgery.

\section{PHLF - The Problem of Definition}

So far, there is no standardized definition or terminology for the PHLF [4].

In 2010, Rahbari and other members of the International Study Group of Liver Surgery (ISGLS) defined PHLF as 'a postoperative acquired deterioration in the ability of the liver to maintain its synthetic, excretory and detoxifying functions, which are characterized by an increased international normalized ratio and concomitant hyperbilirubinemia on or after postoperative (POD) 5 (table 1) [4].

The ISGLS differentiated also the severity of PHLF in 3 grades from $\mathrm{A}$ to $\mathrm{C}$. The classification is shown in table 2 .

There are still numerous other definitions of PHLF in the literature. These definitions usually depend on countries and hospitals. They contain blood chemistry results and clinical examination in different variations. For example, in the study of Eguschi et al. [5] in 2000, PHLF was diagnosed when three findings were present in the patient: (1) hepatic encephalopathy, (2) progressive hyperbilirubinemia and (3) reduced hepaplastin test.

Since the ISGLS definition is easily comparable, it should be used widely.

\section{KARGER \\ Fax +4161306 1234 \\ E-Mail karger@karger.ch}

www.karger.com

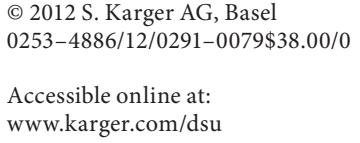

Prof. Dr. med. Wolf O. Bechstein

Department of General and Visceral Surgery, Johann Wolfgang Goethe University

Theodor-Stern-Kai 7

DE-60528 Frankfurt am Main (Germany)

Tel. +49696301 5251, E-Mail Wolf.Bechstein@kgu.de 
Table 1. Consensus definition and severity grading of posthepatectomy liver failure by the ISGLS [4]

Definition:

A postoperatively acquired deterioration in the ability of the liver (in patients with normal and abnormal liver function) to maintain its synthetic, excretory and detoxifying function, characterized by an increased INR (or need of clotting factors to maintain normal INR) and hyperbilirubinemia (according to the normal cutoff levels defined by the local laboratory) on or after postoperative day 5 . If INR or increasing INR (decreasing prothrombin time) and increasing serum bilirubin concentration on or after postoperative day 5 (compared with the values of the previous day). Other obvious causes for the observed biochemical and clinical alterations such as biliary obstruction should be ruled out.

\begin{tabular}{ll} 
Grade & \\
\hline A & $\begin{array}{l}\text { PHLF resulting in abnormal laboratory parameters but } \\
\text { requiring no change in the clinical management of the } \\
\text { patient }\end{array}$ \\
\hline B $\quad \begin{array}{l}\text { PHLF resulting in a deviation from the regular clinical } \\
\text { management but manageable without invasive treatment }\end{array}$ \\
\hline C & $\begin{array}{l}\text { PHLF resulting in a deviation from the regular clinical } \\
\text { management and requiring invasive treatment }\end{array}$
\end{tabular}

INR = International normalized ratio.

\section{Incidence of PHLF - Still a Serious Complication}

The incidence of PHLF varies in the literature between 1.2 and $32 \%$; in the most recent literature, the incidence is up to $8 \%[3,4]$. The wide range reflects the differences in patient populations and performed procedures. Decrease in PHLF in the last years can be explained by the improvement in surgical techniques and in intensive care medicine. But also risk factors of the patient population seem to have a big influence on the occurrence of PHLF.

\section{Risk Factors and Risk Assessment for PHLF}

Identification of risk factors is important to decrease the incidence of PHLF. Three groups of risk factors can be differentiated (table 3):

- Patient related - right selection of the patients can prevent PHLF

- Surgery related - improvement in technique can prevent PHLF
- Related to postoperative management - avoiding of machine ventilation, vasopressors and hepatotoxic drugs may decrease the incidence of PHLF.

\section{Patient-Related Risk Factors}

Various patient-related risk factors have been described such as age or comorbidity.

Important risk factors for PHLF are pre-existing liver diseases, e.g. steatosis, cirrhosis, cholangitis and chemotherapy-associated hepatotoxicity [6]. But also active viral hepatitis can increase the risk of PHLF.

Steatosis of the liver seems to be associated with a higher perioperative rate of complications and increased incidence of PHLF. Patients with a biopsy-proven moderate steatosis showed a higher incidence of PHLF compared to patients with normal liver parenchyma [7].

Although morbidity increased in patients with preoperative cholestasis, no increased risk for PHLF could be demonstrated [8].

The influence of fibrosis or cirrhosis of the liver on the risk of PHLF in patients undergoing liver resections is still a subject of controversy. Several studies showed an increased risk of PHLF for these patients [9], whereas others could not show this fact so clearly [10]. This may be caused by a more restrictive indication for liver surgery in these patients. In summary, there is no doubt that patients suffering from liver cirrhosis have a risk for PHLF depending on the functional reserve of the liver preoperatively.

In 2000, Eguchi et al. [5] analyzed the outcome of patients undergoing hepatectomy with cirrhosis associated with active hepatitis. Patients with liver cirrhosis and absence of hepatitis had the same mortality rate as patients with chronic hepatitis (3.3 vs. $2.9 \%$ ). Mortality was significant higher in patients that underwent resection of hepatocellular carcinoma (HCC) in cirrhosis associated with active hepatitis (8.7 vs. $1.5 \%$; $\mathrm{p}<0.05$ ) [5].

Besides cirrhosis for various reasons, preoperative chemotherapy resulting in CASH (chemotherapy-associated steatohepatitis) or sinusoidal obstruction is a defined risk factor for PHLF as well.

In their study, Tanaka et al. [11] analyzed the influence of chemotherapy on liver regeneration. They found no difference in liver regeneration between patients with colorectal liver metastases after chemotherapy who underwent portal vein embolization or first hepatectomy. There was only a significant lower liver hypertrophy between patients with steatosis and patients without steatosis of the liver $(\mathrm{p}=0.04)$ [11]. 
Table 2. Grading criteria of PHLF defined by ISGLS

\begin{tabular}{|c|c|c|c|}
\hline & Grade A & Grade B & Grade C \\
\hline $\begin{array}{l}\text { Specific } \\
\text { treatment }\end{array}$ & Not required & $\begin{array}{l}\text { Fresh frozen plasma } \\
\text { Albumin } \\
\text { Daily diuretics } \\
\text { Noninvasive ventilation } \\
\text { Transfer to IMC/ICU }\end{array}$ & $\begin{array}{l}\text { Transfer to ICU } \\
\text { Circulatory support (vasoactive drugs) } \\
\text { Hemodialysis } \\
\text { Intubation and mechanical ventilation } \\
\text { Extracorporal liver support } \\
\text { Rescue hepatectomy/liver transplantation }\end{array}$ \\
\hline $\begin{array}{l}\text { Hepatic } \\
\text { function }\end{array}$ & $\begin{array}{l}\text { Adequate coagulation }(\text { INR }<1.5) \\
\text { No neurological symptoms }\end{array}$ & $\begin{array}{l}\text { Inadequate coagulation (INR } \geq 1.5<2.0 \text { ) } \\
\text { Beginning of neurologic symptoms } \\
\text { (i.e. somnolence, confusion) }\end{array}$ & $\begin{array}{l}\text { Inadequate coagulation }(\mathrm{INR} \geq 2.0) \\
\text { Severe neurologic symptoms/hepatic } \\
\text { encephalopathy }\end{array}$ \\
\hline $\begin{array}{l}\text { Renal } \\
\text { function }\end{array}$ & $\begin{array}{l}\text { Adequate urine output } \\
(\geq 0.5 \mathrm{ml} / \mathrm{kg} / \mathrm{h}), \text { BUN }<150 \mathrm{mg} / \mathrm{dl} \text {, } \\
\text { no symptoms of uremia }\end{array}$ & $\begin{array}{l}\text { Inadequate urine output }(\leq 0.5 \mathrm{ml} / \mathrm{kg} / \mathrm{h}) \text {, } \\
\mathrm{BUN}<150 \mathrm{mg} / \mathrm{dl} \text {, no symptoms of } \\
\text { uremia }\end{array}$ & $\begin{array}{l}\text { Renal dysfunction not manageable with } \\
\text { diuretics, BUN } \geq 150 \mathrm{mg} / \mathrm{dl} \text {, symptoms } \\
\text { of uremia }\end{array}$ \\
\hline $\begin{array}{l}\text { Pulmonary } \\
\text { function }\end{array}$ & $\begin{array}{l}\text { Arterial oxygen saturation }>90 \% \\
\text { May have oxygen supply via nasal } \\
\text { cannula or oxygen mask }\end{array}$ & $\begin{array}{l}\text { Arterial oxygen saturation }<90 \% \text { despite } \\
\text { oxygen supply via nasal cannula or } \\
\text { oxygen mask }\end{array}$ & $\begin{array}{l}\text { Severe refractory hypoxemia } \\
\text { (arterial oxygen saturation } \leq 85 \% \text { with } \\
\text { high fraction of inspired oxygen }\end{array}$ \\
\hline $\begin{array}{l}\text { Additional } \\
\text { evaluation }\end{array}$ & Not required & $\begin{array}{l}\text { Abdominal ultrasonography/CT, } \\
\text { chest radiography, sputum, blood, } \\
\text { urine culture, brain CT }\end{array}$ & $\begin{array}{l}\text { Abdominal ultrasonography/CT, } \\
\text { chest radiography, sputum, blood, } \\
\text { urine culture, brain CT } \\
\text { ICP monitoring device }\end{array}$ \\
\hline
\end{tabular}

\section{Surgery-Related Risk Factors}

Risk factors for PHLF which are related to surgical procedure and perioperative management are the extent of the resection with influence on the size of the future liver remnant (FLR), the time of the Pringle maneuver and operation, and the need for blood transfusion during operation.

The minimal functional liver mass needed for adequate liver function is estimated to be $20-25 \%$ if patients have a normal liver parenchyma. Patients with abnormal parenchyma (steatosis, fibrosis or cirrhosis) need an FLR up to $40 \%$ as minimal functional liver mass [12].

But also intraoperative blood loss $>1,000 \mathrm{ml}$ increases the risk of PHLF $[6,13]$. This effect is caused by a fluid shift following excessive blood loss and causes a systemic inflammation because of bacterial transmission. But also coagulopathy following blood loss seems to increase the risk of intra-abdominal hematomas and bacterial infections [14].

A third surgical risk factor which was identified for increased PHLF is prolonged operation time.

\section{Risk Factors Related to Postoperative Management}

To prevent the occurrence of PHLF, adequate risk assessment at the right time is necessary. It is important to differentiate between pre- and postoperative risk assessment.
Table 3. Risk factors for PHLF [6]

\begin{tabular}{ll}
\hline Patient related & $\begin{array}{l}\text { Pre-existent liver diseases (cirrhosis, steatosis, } \\
\text { fibrosis, cholangitis) } \\
\text { Neoadjuvant treatment because of chemother- } \\
\text { apy-associated hepatotoxicity } \\
\text { Male gender } \\
\text { Advanced age ( }>65 \text { years) } \\
\text { Comorbidity } \\
\text { Malnutrition }\end{array}$ \\
\hline Surgery related & $\begin{array}{l}\text { Small remnant liver volume } \\
\text { Excessive intraoperative blood loss }(>1,250 \mathrm{ml})\end{array}$ \\
& Prolonged operation time \\
\hline Miscellaneous & $\begin{array}{l}\text { Hepatic parenchymal congestion } \\
\text { Ischemia-reperfusion injury } \\
\text { Infection }\end{array}$ \\
\hline
\end{tabular}

\section{Preoperative Risk Assessment}

Preoperative risk assessment should include physical examination to clarify the following questions (table 4):

- Comorbid conditions such as diabetes mellitus, pulmonal, renal or cardiovascular diseases

- Pre-existing liver diseases like steatosis, cirrhosis, fibrosis, hepatitis 
Table 4. Risk assessment

\begin{tabular}{ll}
\hline $\begin{array}{l}\text { Preoperative } \\
\text { risk assessment }\end{array}$ & $\begin{array}{l}\text { Clinical assessment of patient } \\
\text { Measurement of FLR with CT volumetry } \\
\text { Measurement of function of FLR with } \\
\text { hepatobiliary scintigraphy }\end{array}$ \\
\hline $\begin{array}{l}\text { Postoperative } \\
\text { risk assessment }\end{array}$ & $\begin{array}{c}\text { Patient's clinical presentation: ascites, } \\
\text { encephalopathy, organ failure }\end{array}$ \\
& $\begin{array}{c}\text { Intensive care scoring systems like } \\
\text { APACHE III }\end{array}$ \\
& $\begin{array}{c}\text { 50-50 criteria on POD 3 and 5 } \\
\text { MELD }>8 \text { on POD 5 } \\
\text { Fulfillment of PHLF definition (following the } \\
\text { ISGLS definition) }\end{array}$ \\
\hline
\end{tabular}

- Patient's characteristics: age, weight and alcohol consumption.

Another important point is the determination of the FLR. There are different opportunities to measure the FLR.

Besides sonography and MRI, CT volumetry is the method of choice to measure the size of FLR. Dello et al. $[15,16]$ could show that also non-radiologists can perform an adequate measurement of FLR with free, opensource software packages.

But also with improvement in imaging techniques, there are still patients with a sufficient FLR size resulting in PHLF after surgery. In their study in 2006, Dinant et al. [17] analyzed a possible cause of this discrepancy. They showed a difference between volume of FLR and its function. A preoperative decreased ${ }^{99 \mathrm{~m}} \mathrm{Tc}$-mebrofenin uptake in hepatobiliary scintigraphy was a significant risk factor for liver failure and mortality $(p=0.003)$ [17]. In conclusion, the measurement of ${ }^{99 \mathrm{~m} T c-m e b r o f e n i n ~ u p t a k e ~ i n ~}$ FLR is more valuable in assessing the risk of liver failure than CT volumetry of FLR.

\section{Postoperative Risk Assessment}

Early risk assessment for PHLF allows a prediction of outcome after liver resection. Together with the extent of the resection and the intraoperative course, it can help identify patients needing intensified treatment [18].

Of course, the clinical presentation of the patient and his symptoms is the most important assessment for an increased risk of PHLF. If the patient has developed ascites, encephalopathy or extrahepatic organ failure, the postoperative risk for prolonged clinical course is increased and poor outcome is probable. Particularly in the intensive care course, in addition to the subjective assessment, objective markers are necessary to initiate appropriate treatments as early as possible.

Easy for daily use is the determination of C-reactive protein (CRP). Because CRP is produced in the liver, Rahman et al. [19] postulated a dampened CRP could be sign of liver failure. They were able to show that patients developing a PHLF had a significant lower CRP level on POD 1 than patients without PHLF [19].

Another useful tool for determining PHLF is the so called '50-50' criteria. They are composed of a prothrombin time less than $50 \%$ and a serum bilirubin level $>50 \mu \mathrm{mol} / \mathrm{l}$ on POD 3 and 5 as a predictive marker for increased mortality [20]. It was shown in recent studies that these criteria allow an early diagnosis of PHLF. But it was also shown that the 50-50 criteria are not a significant marker for increased morbidity after liver surgery [18].

The MELD (model for end-stage liver disease) system can be used for assessment of PHLF as well. MELD is used for patients with HCC undergoing liver resection to assess their perioperative morbidity and mortality [21]. Today, it is especially used for allocation of liver transplantation candidates. Rahbari et al. [18] could show in a comparison of MELD, 50-50 criteria and PHLF definition of ISGLS that MELD score $>8$ on POD 5 helps to identify patients with increased morbidity. They showed a sensitivity of $55 \%$ for prediction of morbidity and $71 \%$ for prediction of mortality. The same study also showed the sensitivity for morbidity and mortality for the ISGLS criteria of PHLF of 23 and 65\% [18], respectively. In conclusion, the MELD score gave the best early prediction of increased morbidity and mortality after liver surgery, and the PHLF definition was able to assess the risk for increased mortality [18].

During treatment in the ICU, the Acute Physiology and Chronic Health Evaluation (APACHE) score is used to predict the outcome of patients in the ICU. The APACHE system was introduced in 1981 by Knaus et al. [22] for prediction of mortality in the ICU. Because of advances in intensive care medicine, the system had to be updated, and currently APACHE III score is used. In 1998, Hamahata et al. [23] demonstrated that APACHE III score gives a sufficient prediction of mortality after liver resection. Unfortunately, this study was only performed on patients with cholangiocellular carcinoma, and up to now there have been no further analyses for other groups of patients after liver resections. 


\section{Prevention of PHLF - What Can Be Done to Avoid PHLF?}

First of all, there are risk factors which cannot be influenced like age, gender, existence of cirrhosis or fibrosis and diagnosis of the patient. This has led to a careful indication for liver resections. Patients in poor general condition have a higher risk for perioperative complications and PHLF. But there are possibilities to improve patient general condition and to decrease risk factors for PHLF like small liver remnant volume.

\section{Improving Patient's Clinical Condition}

Liver surgery candidates should fulfill the criteria for general operational capability. Comorbid conditions should be optimized before surgery as much as possible. The Classification of the American Society of Anesthesia gives a good overview of general capability of the patient.

No improvement in postoperative course and outcome may be prevented with preoperative weight reduction in patients with overweight or obesity. In a study of Cuchetti et al. [24], it was shown that liver surgery can be performed safely in overweight and obese patients with HCC. There was only a significantly increase in mild respiratory complications $(\mathrm{p}=0.044)$ in these $\mathrm{pa}$ tients.

On the other hand, many patients undergoing liver surgery suffer from malignant diseases or from advanced liver diseases and have a bad nutritional status [25]. To decrease the risk of general complications, optimization of nutritional status especially in patients with cirrhosis may be helpful [26], but no relationship between malnutrition and PHLF has been demonstrated [6].

Removal of cholestasis is not a guarantee that PHLF will be avoided either. Different studies tried to show an advantage in patients with jaundice getting percutaneous transhepatic drainage (PTC) before liver surgery, but there was never a significant improvement in outcome. Normally, PTC-related complications led to an increase in overall complications [27].

\section{Improving Size and Function of FLR}

As mentioned above, patients with normal liver parenchyma need about 25\% FLR in order to have an adequate liver function after surgery. Preoperative strategies to increase the size of the FLR are a useful tool in PHLF prevention.

First of all, it is possible to be cautious by the extent of resection. Further possibilities are two-stage hepatecto- my, downsizing with neoadjuvant chemotherapy and hypertrophy induction.

In patients with normal liver function, portal vein embolization of the diseased side of the liver is one way to avoid small liver remnant. With portal vein embolization, a volume increase from 28 up to $46 \%$ is obtainable depending on pre-existing liver disease $[28,29]$.

\section{Improving Intraoperative Course}

As excessive intraoperative blood loss is a risk factor for PHLF, improvement in dissection technologies in the last years has led to a decrease in the volume of blood loss during liver resections and improved postoperative outcome. An easy method to lower blood loss is the use of portal vein clamping. An older study reported a lower blood loss due lowering central venous pressure during dissection to $\leq 5 \mathrm{~mm} \mathrm{Hg}$ [30]. A possible way to avoid ischemic damage in the liver remnant seems to be the socalled ischemic precondition. It means a temporal clamping of portal triad before a prolonged clamping. It was shown that this helps to reduce hepatocyte damage and is associated with less morbidity, but there was no influence on PHLF occurrence [31].

\section{Improving Postoperative Management}

Adequate postoperative monitoring is essential to predict postoperative complications early enough. Postoperative liver enzymes, albumin, creatinine and blood coagulation should be monitored, and patients should be clinically reevaluated on a regular basis.

Patients that develop complications like encephalopathy, hypocoagulation or jaundice should be placed in intermediate care (IMC) or in the ICU for better monitoring, and should be checked for PHLF development.

\section{Treatment of PHLF Remains Difficult}

Although surgical techniques and postoperative treatment has improved in the last years, treatment of PHLF still remains difficult.

If PHLF is detected in a patient, it should be scored by the ISGLS system. PHLF grade A should be monitored well, but will normally not be in need of specific treatment. If PHLF grade B occurs, it has to be evaluated if the patient should be placed in IMC or in the ICU. Patients with PHLF grade $\mathrm{C}$ need invasive treatment and have to be placed in the ICU [4].

Pulmonary, renal and circulatory disturbances should be treated with a goal-directed therapy regime. Diuretics 
and renal replacement therapy have to be used as indicated. In cases of pulmonary insufficiency, noninvasive or invasive ventilation has to be used [4].

For specific treatment of hepatic insufficiency, there are still little options. Goal-directed therapy means application of human albumin, fresh frozen plasma PPSB or AT III to cover the liver function [6].

Liver support systems have been available for some years now:

- Molecular absorbent recirculating system (MARS ${ }^{\circledR}$ )

- Modified fractionated plasma separation and adsorption (Prometheus ${ }^{\circledR}$ )

- Bioartificial liver and extracorporal liver assist device.

\section{Molecular Absorbent Recirculating System}

MARS is an extracorporeal albumin dialysis where blood is dialyzed against an albumin-enriched solution. There are only few studies dealing with the use of MARS in cases of PHLF. Van de Kerkhove et al. [32] reported on 5 patients in the Netherlands who were treated with MARS because of PHLF. Three patients showed significant improvement in clinical course, and all patients showed improvement in biochemical parameters. But only one patient survived. Also a study from Hong Kong Hospitals showed a poor outcome in patients with PHLF and MARS therapy despite of improvement in biochemical parameters [33].

It seems that MARS therapy improved clinical and biochemical parameters, although patients died of other complications before their liver function could recover. Since there is a persistent lack of randomized data, all questions concerning the modality of MARS treatment, like time point or duration, are still unanswered.

\section{Modified Fractionated Plasma Separation and} Adsorption (Prometheus)

The Prometheus system also uses albumin dialysis as principle. Albumin-bound toxins are eliminated through an albumin-permeable membrane, and cleaned albumin is returned to a patient. Prometheus seems to have a better detoxifying capacity than MARS, but there is also a lack of data regarding its use in PHLF, so future studies have to show if it will become a standardized therapy for PHLF.

\section{Liver Transplantation}

Patients that have no contraindications for liver transplantation can be considered as liver transplantation candidates if severe PHLF occurs. In the daily praxis, however, most indications for liver resections are contraindications for liver transplantation, and therefore this option usually is not an alternative.

\section{Conclusion}

PHLF remains a serious and life-threatening problem in patients with major liver resections or limited functional reserve due to preexisting liver disease. Adequate preoperative risk assessment of liver function and general condition, gentle and parenchyma-sparing surgery and optimal postoperative treatment are essential in PHLF prevention. Early diagnosis of PHLF can help initiate treatment in the ICU to optimize and recover both hepatic and extrahepatic organ function. Extracorporeal liver devices are still experimental medicine, and their use can only be recommended in prospective randomized trials.

\section{References}

1 Benzoni E, Lorenzin D, Baccarani U, Adani GL, Favero A, Cojutti A, Bresadola F, Uzzau A: Resective surgery for liver tumor: a multivariate analysis of causes and risk factors linked to postoperative complications. Hepatobiliary Pancreat Dis Int 2006;5:526-533.

$\checkmark 2$ Schroeder RA, Marroquin CE, Bute BP, Khuri S, Henderson WG, Kuo PC: Predictive indices of morbidity and mortality after liver resection. Ann Surg 2006;243:373-379.

-3 Paugam-Burtz C, Janny S, Delefosse D, Dahmani S, Dondero F, Mantz J, Belghiti J: Prospective validation of the 'fifty-fifty' criteria as an early and accurate predictor of death after liver resection in intensive care unit patients. Ann Surg 2009;249:124-128.
-4 Rahbari NN, Garden OJ, Padbury R, BrookeSmith M, et al: Posthepatectomy liver failure: a definition and grading by the International Study Group of Liver Surgery (ISGLS). Surgery $2011 ; 149: 713-724$.

5 Eguchi H, Umeshita K, Sakon M, Nagano H, et al: Presence of active hepatitis associated with liver cirrhosis is a risk factor for mortality caused by posthepatectomy liver failure. Dig Dis Sci 2000;45:1383-1388.

6 van den Broek MA, Olde Damink SW, Dejong $\mathrm{CH}$, Lang H, Malagó M, Jalan R, Saner FH: Liver failure after partial hepatic resection: definition, pathophysiology, risk factors and treatment. Liver Int 2008;28:767780 .
7 Behrns KE, Tsiotos GG, DeSouza NF, Krishna MK, Ludwig J, Nagorney DM: Hepatic steatosis as a potential risk factor for major hepatic resection. J Gastrointest Surg 1998;2: 292-298.

$>8$ Cherqui D, Benoist S, Malassagne B, Humeres R, Rodriguez V, Fagniez PL: Major liver resection for carcinoma in jaundiced patients without preoperative biliary drainage. Arch Surg 2000;135:302-308.

$\checkmark 9$ Poon RT, Fan ST: Hepatectomy for hepatocellular carcinoma: patient selection and postoperative outcome. Liver Transpl 2004; 10(suppl 1):S39-S45. 
10 Yang T, Zhang J, Lu JH, Yang GS, Wu MC, Yu WF: Risk factors influencing postoperative outcomes of major hepatic resection of hepatocellular carcinoma for patients with underlying liver diseases. World J Surg 2011;35: 2073-2082.

- 11 Tanaka K, Kumamoto T, Matsuyama R, Takeda K, Nagano Y, Endo I: Influence of chemotherapy on liver regeneration induced by portal vein embolization or first hepatectomy of a staged procedure for colorectal liver metastases. J Gastrointest Surg 2010;14: 359-368.

-12 Shirabe K, Shimada M, Gion T, Hasegawa H, Takenaka K, Utsunomiya T, Sugimachi K: Postoperative liver failure after major hepatic resection for hepatocellular carcinoma in the modern era with special reference to remnant liver volume. J Am Coll Surg 1999; 188:304-309.

13 Jarnagin WR, Gonen M, Fong Y, DeMatteo RP, Ben-Porat L, Little S, Corvera C, Weber $S$, Blumgart LH: Improvement in perioperative outcome after hepatic resection: analysis of 1,803 consecutive cases over the past decade. Ann Surg 2002;236:397-406, discussion 406-407.

14 Kooby DA, Stockman J, Ben-Porat L, Gonen $\mathrm{M}$, Jarnagin WR, et al: Influence of transfusions on perioperative and long-term outcome in patients following hepatic resection for colorectal metastases. Ann Surg 2003; 237:860-869, discussion 869-870.

-15 Dello SA, Stoot JH, van Stiphout RS, Bloemen JG, Wigmore SJ, Dejong CH, van Dam RM: Prospective volumetric assessment of the liver on a personal computer by nonradiologists prior to partial hepatectomy. World J Surg 2011;35:386-392.

- 16 Dello SA, van Dam RM, Slangen JJ, van de Poll MC, et al: Liver volumetry plug and play: do it yourself with ImageJ. World J Surg 2007;31:2215-2221.
17 Dinant S, de Graaf W, Verwer BJ, Bennink RJ, et al: Risk assessment of posthepatectomy liver failure using hepatobiliary scintigraphy and CT volumetry. J Nucl Med 2007;48:685692.

18 Rahbari NN, Reissfelder C, Koch M, Elbers H, Striebel F, Büchler MW, Weitz J: The predictive value of postoperative clinical risk scores for outcome after hepatic resection: a validation analysis in 807 patients. Ann Surg Oncol 2011;18:3640-3649.

19 Rahman SH, Evans J, Toogood GJ, Lodge PA Prasad KR: Prognostic utility of postoperative C-reactive protein for posthepatectomy liver failure. Arch Surg 2008;143:247-253, discussion 253.

20 Balzan S, Belghiti J, Farges O, Ogata S, Sauvanet $A$, Delefosse D, Durand F: The ' $50-50$ criteria' on postoperative day 5: an accurate predictor of liver failure and death after hepatectomy. Ann Surg 2005;242:824-828, discussion 828-829.

21 Cucchetti A, Ercolani G, Cescon M, Ravaioli M, Zanello M, et al: Recovery from liver failure after hepatectomy for hepatocellular carcinoma in cirrhosis: meaning of the model for end-stage liver disease. J Am Coll Surg 2006;203:670-676.

22 Knaus WA, Zimmerman JE, Wagner DP, Draper EA, Lawrence DE: APACHE-Acute Physiology and Chronic Health Evaluation: a physiologically based classification system. Crit Care Med 1981;9:591-597.

23 Hamahata N, Nagino M, Nimura Y: APACHE III, unlike APACHE II, predicts posthepatectomy mortality in patients with biliary tract carcinoma. Acute Physiology and Chronic Health Evaluation. Crit Care Med 1998;26:1671-1676.

-24 Cucchetti A, Cescon M, Ercolani G, Di Gioia P, Peri E, Pinna AD: Safety of hepatic resection in overweight and obese patients with cirrhosis. Br J Surg 2011;98:1147-1154.

25 Read JA, Choy ST, Beale PJ, Clarke SJ: Evaluation of nutritional and inflammatory status of advanced colorectal cancer patients and its correlation with survival. Nutr Cancer 2006;55:78-85.
26 Merli M, Nicolini G, Angeloni S, Riggio O: Malnutrition is a risk factor in cirrhotic patients undergoing surgery. Nutrition 2002; 18:978-986.

$\checkmark 27$ Sewnath ME, Karsten TM, Prins MH, Rauws EJ, Obertop H, Gouma DJ: A meta-analysis on the efficacy of preoperative biliary drainage for tumors causing obstructive jaundice. Ann Surg 2002;236:17-27.

28 Azoulay D, Castaing, D, Smail A, Adam R, Cailliez V, et al: Resection of nonresectable liver metastases from colorectal cancer after percutaneous portal vein embolization. Ann Surg 2000;231:480-486.

$>29$ Azoulay D, Castaing D, Krissat J, Smail A, Hargreaves GM, Lemoine A, et al: Percutaneous portal vein embolization increases the feasibility and safety of major liver resection for hepatocellular carcinoma in injured liver. Ann Surg 2000;232:665-672.

30 Vassiliou I, Arkadopoulos N, Stafyla V, Theodoraki K, Yiallourou A, et al: The introduction of a simple maneuver to reduce the risk of postoperative bleeding after major hepatectomies. J Hepatobiliary Pancreat Surg 2009; 16:552-556.

31 Gurusamy KS, Kumar Y, Pamecha V, Sharma D, Davidson BR: Ischaemic pre-conditioning for elective liver resections performed under vascular occlusion. Cochrane Database Syst Rev 2009;CD007629.

-32 van de Kerkhove MP, de Jong KP, Rijken AM, de Pont AC, van Gulik TM: MARS treatment in posthepatectomy liver failure. Liver Int 2003;23(suppl 3):44-51.

33 Chiu A, Chan LM, Fan ST: Molecular adsorbent recirculating system treatment for patients with liver failure: the Hong Kong experience. Liver Int 2006;26:695-702. 